\title{
Microbial profile in infectious keratitis over 8 years in Sao Paulo, Brazil: pathogens and microbial resistance
}

\author{
Luiza Manhezi Shin de Oliveira \\ Hospital das Clínicas da Faculdade de Medicina da Universidade de São Paulo \\ Tatiana Tanaka \\ Hospital das Clínicas da Faculdade de Medicina da Universidade de São Paulo \\ Juliana Mika Kato ( $\nabla$ juliana.kato@hc.fm.usp.br) \\ Hospital das Clínicas da Faculdade de Medicina da Universidade de São Paulo \\ Regina Sayuri Yamashiro Shiotuki \\ Hospital das Clínicas da Faculdade de Medicina da Universidade de São Paulo \\ Karoline de Lemes Giuntini Corrêa \\ Hospital das Clínicas da Faculdade de Medicina da Universidade de São Paulo \\ Thaís Sabato di Gioia \\ Hospital das Clínicas da Faculdade de Medicina da Universidade de São Paulo \\ Flavia Rossi \\ Hospital das Clínicas da Faculdade de Medicina da Universidade de São Paulo \\ Ruth Miyuki Santo \\ Hospital das Clínicas da Faculdade de Medicina da Universidade de São Paulo
}

\section{Research Article}

Keywords: Infectious keratitis, bacterial keratitis, fungal keratitis, antimicrobial resistance

Posted Date: August 23rd, 2021

DOI: https://doi.org/10.21203/rs.3.rs-821172/v1

License: @) (1) This work is licensed under a Creative Commons Attribution 4.0 International License. Read Full License 


\section{Abstract \\ Objective}

Infectious keratitis remains a sight-threatening disease and its prompt diagnosis and treatment are critical. This study investigated the microbiological patterns of isolates in corneal ulcers in a tertiary health center in an 8-year period.

\section{Methods}

Retrospective analysis of scrapes of microbial keratitis performed from January 2013 to December 2020. Demographics and microbiological data were collected.

\section{Results}

A total of 446 scrapes were performed on eyes of 433 patients, 270 male (62.4\%), mean age 51.7 years. 304 organisms were isolated from 248 (55.6\%) positive samples. Polymicrobial infections occurred in 47 samples (19.0\%). Bacterial isolates represented $86.8 \%$ : $53.3 \%$ gram-positive (GP), $33.5 \%$ gramnegative (GN). Cutibacterium acnes (12.2\%) and Pseudomonas aeruginosa (9.9\%) were the most common bacteria. Fungal keratitis comprised $11.8 \%$ of the isolates; Fusarium sp (6.2\%) was the main fungus isolated. GP tested were sensitive to vancomycin, $98.7 \%$ of the GN were sensitive to ceftazidime. All Pseudomonas aeruginosa were sensitive to gentamicin and ciprofloxacin.

\section{Conclusion}

Gram-positive bacteria were predominant in keratitis isolates. In severe bacterial keratitis in our area, vancomycin should be considered as empirical treatment.

\section{Introduction}

Infectious keratitis is an ophthalmology emergency that remains sight-threatening and can lead to severe complications, such as corneal perforation, endophthalmitis and phthisis bulbi. Corneal scarring and vascularization are common causes of blindness among children and adults ${ }^{1,2}$. According to a systematic review from 2000 to 2010 , corneal opacities were the fourth cause of blindness globally 3 .

Clinically, it manifests itself as eye pain, redness, decreased vision, ocular discharge and photophobia. The slit-lamp biomicroscopy findings include cilliary injection, epithelial defect, suppurative stromal infiltrates or melting, corneal edema, hypopyon and anterior chamber inflammation ${ }^{2}$. The prompt diagnosis, agent detection and early medical therapy are imperative to avoid vision impairment, blindness and other ocular sequelae $e^{2,4}$.

Before microbiological data is available, there is a strategy of using empirical fortified antibiotics or starting the treatment with a fluoroquinolone. This monotherapy with a fluoroquinolone has been seen as effective as the combined fortified option, with good ocular penetration and a smaller risk of ocular discomfort and chemical conjunctivitis ${ }^{2,5}$.

The etiology of corneal infection depends on the geography, climate, and socioeconomic status of the countries, as well as ocular diseases endemic in each area. There are different patterns in urban and rural areas as well. Therefore it is important to know the regional microbiological profile to better understand the epidemiology of the disease and decide on the best treatment protocol ${ }^{1,2,6-8}$.

This study aimed to review the etiology and antimicrobial patterns of isolates in scrapes of corneal ulcers in patients referred to a university hospital in Sao Paulo, Brazil in an 8-year period.

\section{Methods}

A retrospective analysis of charts and corneal scrapes results of patients clinically diagnosed with microbial keratitis at the Department of Ophthalmology, Hospital das Clinicas, University of Sao Paulo, School of Medicine, Sao Paulo, Brazil, was performed from January 2013 to December 2020 . This study was approved by the Institutional Ethics Committee (CAAE: 67891817.8.0000.0068). All microbiological examinations were conducted at the Department of Microbiology of our Institution, in accordance with relevant guidelines and regulations. Demographics and microbiological data were collected. All patients signed an informed consent approving participation in the study and approving the publication of their images.

Samples for culture were obtained from corneal infiltrate greater than $2 \mathrm{~mm}$ in size, centrally located, with deep stromal involvement or melting. Corneal scraping was carefully performed under direct visualization in a slit lamp biomicroscope with topical anesthesia (0.5\% proxymetacaine hydrochloride, Anestalcon $^{\text {TM }}$ - Alcon Labs, Brazil). Samples were obtained from the margin of the lesions using steel spatulas that were changed for each smear. Specimens were immediately placed on glass plates for Gram stain and also inoculated into the following media: saline solution, thioglycollate broth, brain heart infusion broth with antibiotics, blood agar, chocolate agar and Sabouraud dextrose agar. Since 2018, the non-nutrient agar lawned with Escherichia coli has been available for culture if there is suspicion of Acanthamoeba keratitis. Inoculated media were promptly taken to the laboratory. After scraping, empirical treatment was initiated with fortified topical antibiotics: a cephalosporin (cefazoline) and an aminoglycoside (gentamicin or amikacin) hourly. If fungi etiology was suspected, topical natamycin was added to the regimen. 
The pathogens of positive samples were identified and analyzed by the Matrix-assisted laser desorption ionization time of flight (MALDI-TOF) mass spectrometry (Vitek MS ${ }^{\text {TM }}$ system, bioMérieux, Marcyl'Etoile, France); the antimicrobial susceptibility testing (AST) was performed using Vitek ${ }^{\text {TM }}$ and tests disk diffusion method (Kirby-Bauer, 1966). Evaluation of the zone diameters followed the Clinical and Laboratory Standards Institute (CLSI) current guidelines of each period ${ }^{9-11}$.

\section{Results}

Over these 8 years, a total of 446 consecutive corneal scrapes were performed on eyes of 433 patients, 163 female (37.6\%) and 270 male (62.4\%), mean age $51.7+/-21.0$ years (1 to 90). The mean number of corneal scrapings per year was 55.7 (21 to 100). A total of 304 organisms were isolated from 248 (55.6\%) positive samples. The percentage of positive cultures per year ranged from $41.7-66.7 \%$ in these 8 years. Infections due to a single organism occurred in 201 (81.0\%) of the samples, and multiple agent were found in 47 (19.0\%). (Table 1 and Graphic 1)

Table 1

Corneal scrapes analysis over the 8 years

\begin{tabular}{|c|c|c|c|c|c|c|c|c|c|}
\hline Year & 2013 & 2014 & 2015 & 2016 & 2017 & 2018 & 2019 & 2020 & 2013 to 2020 \\
\hline Gram-positive & 37 (52.1\%) & $\begin{array}{l}9 \\
(30 \%)\end{array}$ & $25(51.0 \%)$ & $\begin{array}{l}8 \\
(47.0 \%)\end{array}$ & $24(70.6 \%)$ & $14(45.2 \%)$ & $34(60.7 \%)$ & $\begin{array}{l}11 \\
(68.7 \%)\end{array}$ & $162(53.3 \%)$ \\
\hline Gram-negative & $23(32.4 \%)$ & $17(56.7 \%)$ & $16(32.7 \%)$ & $\begin{array}{l}8 \\
(47.0 \%)\end{array}$ & $\begin{array}{l}6 \\
(17.6 \%)\end{array}$ & $11(35.5 \%)$ & $17(30.4 \%)$ & $\begin{array}{l}4 \\
(25 \%)\end{array}$ & $102(33.6 \%)$ \\
\hline Fungi & $11(15.5 \%)$ & $\begin{array}{l}4 \\
(13.3 \%)\end{array}$ & $\begin{array}{l}8 \\
(16.3 \%)\end{array}$ & $\begin{array}{l}1 \\
(5.9 \%)\end{array}$ & $\begin{array}{l}4 \\
(11.8 \%)\end{array}$ & $\begin{array}{l}4 \\
(12.9 \%)\end{array}$ & $\begin{array}{l}3 \\
(5.4 \%)\end{array}$ & $\begin{array}{l}1 \\
(6.3 \%)\end{array}$ & $\begin{array}{l}36 \\
(11.8 \%)\end{array}$ \\
\hline Ameba & $\begin{array}{l}0 \\
(0 \%)\end{array}$ & $\begin{array}{l}0 \\
(0 \%)\end{array}$ & $\begin{array}{l}0 \\
(0 \%)\end{array}$ & $\begin{array}{l}0 \\
(0 \%)\end{array}$ & $\begin{array}{l}0 \\
(0 \%)\end{array}$ & $\begin{array}{l}2 \\
(6.5 \%)\end{array}$ & $\begin{array}{l}2 \\
(3.6 \%)\end{array}$ & $\begin{array}{l}0 \\
(0 \%)\end{array}$ & $\begin{array}{l}4 \\
(1.3 \%)\end{array}$ \\
\hline Total of agents & 71 & 30 & 49 & 17 & 34 & 31 & 56 & 16 & 304 \\
\hline $\begin{array}{l}\text { Multiple } \\
\text { isolates }\end{array}$ & $\begin{array}{l}8 \\
(13.1 \%)\end{array}$ & $\begin{array}{l}5 \\
(20.0 \%)\end{array}$ & $\begin{array}{l}8 \\
(20.5 \%)\end{array}$ & $\begin{array}{l}2 \\
(13.3 \%)\end{array}$ & $\begin{array}{l}5 \\
(17.9 \%)\end{array}$ & $\begin{array}{l}5 \\
(19.2 \%)\end{array}$ & $\begin{array}{l}12 \\
(30.0 \%)\end{array}$ & $\begin{array}{l}2 \\
(12.5 \%)\end{array}$ & $\begin{array}{l}45 \\
(18.1 \%)\end{array}$ \\
\hline $\begin{array}{l}\text { Total of } \\
\text { scrapes }\end{array}$ & 100 & 58 & 70 & 36 & 54 & 46 & 61 & 21 & 446 \\
\hline
\end{tabular}

Bacterial isolates accounted for $86.8 \%$ of positive cases: $53.3 \%$ were gram-positive and $33.5 \%$ gram-negative. Cutibacterium acnes (12.2\%), formerly Propionibacterium acnes, Staphylococcus epidermidis (6.6\%) and Streptococcus pneumoniae (6.6\%) were the most common gram-positive bacteria; Pseudomonas aeruginosa (9.9\%) and Serratia marcescens (8.9\%) were the most frequently gram-negative bacteria detected. Fungal keratitis comprised $11.8 \%$ of the total positive cultures; Fusarium sp (6.2\%) and Candida spp (2.3\%) were the main fungi isolated. Acanthamoeba was isolated in 1.3\%. (Table 2) 
Table 2

Organisms Isolated from Scrapes $(n=304)$

\begin{tabular}{|c|c|c|}
\hline Bacteria & 264 & $86.8 \%$ \\
\hline Gram-positive & 162 & $53.3 \%$ \\
\hline Cutibacterium acnes & 37 & $12.2 \%$ \\
\hline Staphylococcus epidermidis & 20 & $6.6 \%$ \\
\hline Streptococcus pneumoniae & 20 & $6.6 \%$ \\
\hline Corynebacterium sp & 19 & $6.2 \%$ \\
\hline Coagulase negative Staphylococcus & 15 & $4.9 \%$ \\
\hline Staphylococcus aureus & 13 & $4.3 \%$ \\
\hline Other Staphylococcus & 13 & $4.3 \%$ \\
\hline Other Streptococcus & 4 & $1.3 \%$ \\
\hline Other gram-positive & 21 & $6.9 \%$ \\
\hline Gram-negative & 102 & $33.5 \%$ \\
\hline Pseudomonas aeruginosa & 30 & $9.9 \%$ \\
\hline Serratia marcescens & 27 & $8.9 \%$ \\
\hline Moraxella sp & 10 & $3.3 \%$ \\
\hline Klebsiella spp & 6 & $2.0 \%$ \\
\hline Other Enterobacterales & 15 & $4.9 \%$ \\
\hline Other gram-negative & 14 & $4.6 \%$ \\
\hline Fungi & 36 & $11.8 \%$ \\
\hline Fusarium sp & 19 & $6.2 \%$ \\
\hline Candida spp & 7 & $2.3 \%$ \\
\hline Aspergillus sp & 3 & $0.9 \%$ \\
\hline Rhodotorula sp & 3 & $0.9 \%$ \\
\hline Other fungi & 4 & $1.3 \%$ \\
\hline Ameba & 4 & $1.3 \%$ \\
\hline Acanthamoeba & 4 & $1.3 \%$ \\
\hline Total of microorganisms & 302 & $100 \%$ \\
\hline
\end{tabular}

Among the 248 positive samples, 143 (57.7\%) antibiograms were performed. We analyzed the susceptibility of Gram-positive species to gentamicin, ciprofloxacin, moxifloxacin, vancomycin, chloramphenicol and tetracycline, which are the topic drugs available in our region. From all gram-positive isolates, the susceptibility to gentamicin was $83.3 \%, 75.9 \%$ to ciprofloxacin, $70.8 \%$ to moxifloxacin, $100 \%$ to vancomycin and chloramphenicol, $60.0 \%$ to tetracycline. The susceptibility of Staphylococcus epidermidis was $72.2 \%$ to gentamicin, $70.6 \%$ to ciprofloxacin, $58.3 \%$ to moxifloxacin and $100 \%$ to vancomycin. The susceptibility of Staphylococcus aureus was $100 \%$ to gentamicin and vancomycin, $83.3 \%$ to ciprofloxacin and moxifloxacin. The susceptibility of Streptococcus pneumoniae was $100 \%$ to vancomycin and chloramphenicol, $60.0 \%$ to tetracycline. Gram-negative species tests to amikacin, gentamicin, ciprofloxacin and ceftazidime were studied. From all gram-negative isolates, the susceptibility to amikacin, ciprofloxacin and ceftazidime was $98.7 \%$ and $97.5 \%$ to gentamicin. The susceptibility of Pseudomonas aeruginosa was $96.8 \%$ to amikacin and ceftazidime, $100 \%$ to gentamicin and ciprofloxacin. The susceptibility of Serratia marcescens was $100 \%$ to these four antibiotics. The susceptibility of the other Enterobacterales (formerly Enterobacteriaceae) tested was $100 \%$ to amikacin and ceftazidime, $90.9 \%$ to gentamicin and $98.7 \%$ to ciprofloxacin. (Table 3 )

Table 3. Antibiotic susceptibility of gram-positive and gram-negative bactéria 


\begin{tabular}{|c|c|c|c|c|c|c|c|c|c|}
\hline Gram (+) & $\begin{array}{l}\text { Isolates } \\
\text { Tested }\end{array}$ & Amikacin & Gentamicin & Ciprofloxacin & Moxifloxacin & Vancomycin & Ceftazidime & Chloramphenicol & Tetrac \\
\hline $\begin{array}{l}\text { Staphylococcus } \\
\text { epidermidis }\end{array}$ & 19 & - & $\begin{array}{l}13 / 18 \\
(72.2 \%)\end{array}$ & $\begin{array}{l}12 / 17 \\
(70.6 \%)\end{array}$ & $\begin{array}{l}7 / 12 \\
(58.3 \%)\end{array}$ & $\begin{array}{l}18 / 18 \\
(100 \%)\end{array}$ & - & - & - \\
\hline $\begin{array}{l}\text { Staphylococcus } \\
\text { aureus }\end{array}$ & 12 & - & $\begin{array}{l}12 / 12 \\
(100 \%)\end{array}$ & $\begin{array}{l}10 / 12 \\
(83.3 \%)\end{array}$ & $\begin{array}{l}10 / 12 \\
(83.3 \%)\end{array}$ & $\begin{array}{l}12 / 12 \\
(100 \%)\end{array}$ & - & - & - \\
\hline $\begin{array}{l}\text { Streptococcus } \\
\text { pneumoniae }\end{array}$ & 20 & - & - & - & - & $\begin{array}{l}20 / 20 \\
(100 \%)\end{array}$ & - & $20 / 20(100 \%)$ & $\begin{array}{l}12 / 20 \\
(60 \%)\end{array}$ \\
\hline All Gram (+) Tested & 83 & - & $\begin{array}{l}25 / 30 \\
(83.3 \%)\end{array}$ & $\begin{array}{l}22 / 29 \\
(75.9 \%)\end{array}$ & $\begin{array}{l}17 / 24 \\
(70.8 \%)\end{array}$ & $\begin{array}{l}50 / 50 \\
(100 \%)\end{array}$ & - & $20 / 20(100 \%)$ & $\begin{array}{l}12 / 20 \\
(60 \%)\end{array}$ \\
\hline Gram (-) & $\begin{array}{l}\text { Isolates } \\
\text { Tested }\end{array}$ & Amikacin & Gentamicin & Ciprofloxacin & Moxifloxacin & Vancomycin & Ceftazidime & Chloramphenicol & Tetrac \\
\hline $\begin{array}{l}\text { Pseudomonas } \\
\text { aeruginosa }\end{array}$ & 31 & $\begin{array}{l}30 / 31 \\
(96.8 \%)\end{array}$ & $\begin{array}{l}31 / 31 \\
(100 \%)\end{array}$ & $\begin{array}{l}31 / 31 \\
(100 \%)\end{array}$ & - & - & $\begin{array}{l}30 / 31 \\
(96.8 \%)\end{array}$ & - & - \\
\hline Serratia marcescens & 27 & $\begin{array}{l}27 / 27 \\
(100 \%)\end{array}$ & $\begin{array}{l}27 / 27 \\
(100 \%)\end{array}$ & $\begin{array}{l}27 / 27 \\
(100 \%)\end{array}$ & - & - & $\begin{array}{l}27 / 27 \\
(100 \%)\end{array}$ & - & - \\
\hline Other Enterobacterales & 22 & $\begin{array}{l}22 / 22 \\
(100 \%)\end{array}$ & $\begin{array}{l}20 / 22 \\
(90.9 \%)\end{array}$ & $\begin{array}{l}21 / 22 \\
(95.5 \%)\end{array}$ & - & - & $\begin{array}{l}22 / 22 \\
(100 \%)\end{array}$ & - & - \\
\hline All Gram (-) Tested & 80 & $\begin{array}{l}79 / 80 \\
(98.7 \%)\end{array}$ & $\begin{array}{l}78 / 80 \\
(97.5 \%)\end{array}$ & $\begin{array}{l}79 / 80 \\
(98.7 \%)\end{array}$ & - & - & $\begin{array}{l}79 / 80 \\
(98.7 \%)\end{array}$ & - & - \\
\hline All isolates tested & 131 & $\begin{array}{l}79 / 80 \\
(98.7 \%)\end{array}$ & $\begin{array}{l}103 / 110 \\
(93.6 \%)\end{array}$ & $\begin{array}{l}101 / 109 \\
(92.7 \%)\end{array}$ & $\begin{array}{l}10 / 12 \\
(83.3 \%)\end{array}$ & $\begin{array}{l}50 / 50 \\
(100 \%)\end{array}$ & $\begin{array}{l}79 / 80 \\
(98.7 \%)\end{array}$ & $20 / 20(100 \%)$ & $\begin{array}{l}12 / 20 \\
(60 \%)\end{array}$ \\
\hline
\end{tabular}

Other Enterobacterales: Citrobacter koseri (diversus), Enterobacter cloacae, Enterococcus faecalis, Escherichia coli, Klebsiella pneumoniae, Klebsiella oxytoca, Morganella morganii, Pantoea agglomerans, Proteus mirabilis, Providencia rettgeri, Raoutella ornithinolytica.

Other Enterobacterales: Citrobacter koseri (diversus), Enterobacter cloacae, Enterococcus faecalis, Escherichia coli, Klebsiella pneumoniae, Klebsiella oxytoca, Morganella morganii, Pantoea agglomerans, Proteus mirabilis, Providencia rettgeri, Raoutella ornithinolytica.

\section{Discussion}

Infectious keratitis is a potentially blinding condition, therefore proper and rapid identification of the causative organism are imperative to guide the management to pursue better visual outcomes. Although early treated patients may successfully recover (Fig. 1), some infections are real challenges and may result in severe complications. (Fig. 2) The main pathogens found in these infections are gram-positive and gram-negative bacteria, fungi and Acanthamoeba. (Fig. 3)

The present study investigated the microbiological patterns of the infectious keratitis of patients admitted to our hospital. The positive rate found in these 8 years was $55.6 \%$, which is in agreement with the rates reported by other authors in Brazil ${ }^{12,13}$, Paraguay $^{14}$, Mexico $^{15}$, United States $^{16,17}$, Canada $^{18}$, United $^{2}$

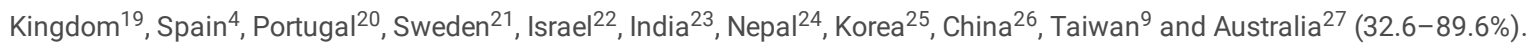

The profile of etiologic pathogens worldwide depends on different risk factors related to specific characteristics of population and environment. Usual predisposing factors related to the individual are occupation, contact lens use, eyelid/ocular or systemic illness, previous ocular traumas or surgeries and use of topical steroids. Environmental-associated risk factors comprises climate, socioeconomic and virulence of the microbial ${ }^{1,7,28}$. Reports from North America, Europe, Australia and Singapore reveal the highest rates of bacterial etiology, regions in which the prevalence of contact lens wear is remarkable ${ }^{28}$. Mycotic keratitis is more frequently reported in developing and tropical countries, particularly in poor rural populations, in which agriculture-related trauma with soil or vegetable matter consists in predisposing factor of fungal ulcer ${ }^{30}$. Reviews from Paraguay ${ }^{14}$, India ${ }^{23}$, China ${ }^{18}$ and Nepal ${ }^{24}$ found $44.5-64.5 \%$ of keratitis with fungal etiology. Other studies from Canada ${ }^{18}$, USA $^{16,17}$, Mexico $^{15}$, Brazil $^{12,13}$, United Kingdom ${ }^{19}$, Spain $^{4}$, Sweden $^{21}$, Portugal $^{20}$, Israel ${ }^{22}$, Korea $^{25}$ and Taiwan $^{8}$ reported rates from $0.2-23.3 \%$ of mycotic keratits.

Bacterial isolates were most of the cases in this review, $86.8 \%$ of the positive isolates, which was similar to studies from Brazil ${ }^{12,13}$, Korea $^{25}$, Taiwan $^{8}$, Israel ${ }^{22}$, Australia ${ }^{26}$ and countries from North America and Europe ${ }^{15-21}$ (76.7-100.0\%). Polymicrobial infection represented $19.0 \%$ of the isolates, comparable to other series $(0.7-26.8 \%)^{4,8,12,17-19,21,22,23-26}$.

The study revealed a predominance of Gram-positive in bacterial keratitis isolates. Cutibacterium acnes (12.2\%) Staphylococcus epidermidis (6.6\%), Streptococcus pneumoniae (6.6\%) and Corynebacterium (6.2\%) were the most common gram-positive bacteria. This high rate of Gram-positive pathogens

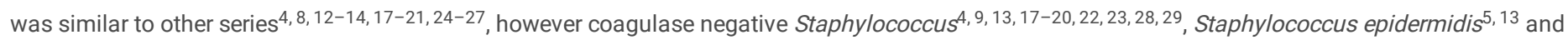
Streptococcus spp. ${ }^{24,25}$ were the most common gram-positive isolated in the literature.

Sagerfors reported anaerobic diphtheroid rods (predominantly C.acnes) as the second main agents in a study performed in Sweden ${ }^{21}$. Tena found $C$. acnes and Corynebacterium as the second and third agent, respectively, in a study from Guadalajara ${ }^{4}$. A New Zealander study also reported C.acnes as the second most common gram-positive bacteria in infectious keratitis, after coagulase negative Staphylococcus ${ }^{29}$. In a Portuguese tertiary centre, the most common 
bacteria was Corynebacterium macginleyi ${ }^{20}$. Although C.acnes ${ }^{30}$ and Corynebacterium may be considered as contaminants, since they are part of eyelid and ocular surface microbiota, its role as pathogenic agents in corneal affections has been described ${ }^{31}$.

In our patients, Pseudomonas aeruginosa was the predominant gram-negative specie isolated, accounting for $9.9 \%$ of the positive samples, which was a similar result to rates in other centers (ranging 2.2-24.4\%) $4,8,12-20,22,23-28$.

Fusarium was the most common fungal isolate (6.2\% of all isolates), also similar to other studies (ranging 2.6-39.5\%) $)^{12-15,18,19,23,24,26}$. Farrell reported

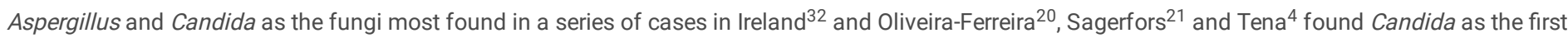
fungal etiology in Portugal, Sweden and Spain, respectively.

All gram-positive tested were sensitive to vancomycin; studies from Korea, Taiwan, United Kingdom, Spain, USA and Canada also described high rates of susceptibility to this antibiotic $(99.4 \%-100 \%) 4,8,17,18,19,24$. There was a high rate of gram-positive resistance to moxifloxacin (29.2\%), higher than the range in other series $(0-6.2 \%)^{24,25}$.

The resistance to ciprofloxacin was found in $24.1 \%$ and $1.3 \%$ of the gram-positive and gram-negative tested, respectively. Other reports also showed higher ciprofloxacin resistance rates in gram-positive bacteria $(10.3-45.0 \%)^{4,17,25}$ than in gram-negative $(1.0-8.8 \%)^{4,8,18,19,26}$. The resistance to gentamicin was $16.7 \%$ and $2.5 \%$ in gram-positive and gram-negative, respectively, which was in accordance with other series findings, that revealed rates ranging from $12.1-$ $19.0 \%$ for gram-positive $4,17,19,25$ and rates ranging from $0-15.3 \%$ for gram-negative bacteria $4,8,17,18,19,25,26$.

The analysis of gram-negative resistance to amikacin and ceftazidime revealed rates of $1.3 \%$ for both antibiotics; other authors reported amikacin resistance rates ranging from $0-11.7 \% 8,17,19,25$ and ceftazidime resistance rates ranging from $0-16.7 \% 4,8,17,18,19,25$.

The method of obtaining the corneal scrapes has been described with many instruments, such as sterile cotton swab, sterile calcium alginate swab, heatsterilized platinum (Kimura) spatula, 26 or 23-gauge needle, blade, cotton-tipped applicator ${ }^{2}$ 33, 34. In our study, we used sterile steel spatulas that were changed for each smear.

In 2020, due to the COVID-19 pandemic, the visits of patients at the Ophthalmology Emergency Room decreased compared to prior years. The number of corneal scrapes was significantly lower than in the other years studied; it happened because the total number of patients presenting infectious keratitis dropped and many patients that were referred to our hospital came with more severe cases of infections, in which the corneal scrape was not safe because of perforation or risk of perforation. Agarwal also reported a reduction in the eye-specific emergency department visits in India ${ }^{35}$.

Our study had some limitations: it was a retrospective review of microbiological data; we did not correlate the laboratory results with the clinical outcomes. Moreover, we could not exclude the possibility that some of our positive isolates could be a result of a contaminant germ or non-pathogenic agent, a part of the ocular surface microbiome of the patients.

\section{Conclusion}

Gram-positive bacteria were predominant in keratitis isolates. Cutibacterium acnes and Pseudomonas aeruginosa were the most common bacteria isolated. Our results suggest that in case of severe bacterial keratitis in our area, vancomycin should be considered as empirical therapy

\section{Declarations}

Author contributions: Conception and design: LMSO, TT and JMK; Data collection: LMSO, RSYS, JMK and KLGC; Drafting manuscript: LMSO and JMK; Data analysis: LMSO, TT, JMK, RSYS, TSG, FR; Critical revision: TT and RMS; Supervision: TT and RMS; All authors reviewed the manuscript and approved the final manuscript.

The authors declare no competing interest.

\section{References}

1. Whitcher, J. P., Srinivasan, M. \& Upadhyay, M. P. Corneal blindness: a global perspective. Bulletin of the World Health Organization, 79, 214-221 (2001).

2. Lin, A. et al. et. al. American Academy of Ophthalmology Preferred Practice Pattern Cornea and External Disease Panel. Bacterial Keratitis Preferred Practice Pattern®., 126 (1), 1-55 https://doi.org/10.1016/j.ophtha.2018.10.018 (2019).

3. Pascolini, D. \& Mariotti, S. P. Global estimates of visual impairment: 2010. The British journal of ophthalmology, 96 (5), 614-618 https://doi.org/10.1136/bjophthalmol-2011-300539 (2012).

4. Tena, D., Rodríguez, N., Toribio, L. \& González-Praetorius, A. Infectious Keratitis: Microbiological Review of 297 Cases. Japanese journal of infectious diseases, 72 (2), 121-123 https://doi.org/10.7883/yoken.JJID.2018.269 (2019).

5. McDonald, E. M., Ram, F. S., Patel, D. V. \& McGhee, C. N. Topical antibiotics for the management of bacterial keratitis: an evidence-based review of high quality randomised controlled trials. The British journal of ophthalmology, 98 (11), 1470-1477 https://doi.org/10.1136/bjophthalmol-2013-304660 (2014).

6. Shah, A., Sachdev, A., Coggon, D. \& Hossain, P. Geographic variations in microbial keratitis: an analysis of the peer-reviewed literature. The British journal of ophthalmology, 95 (6), 762-767 https://doi.org/10.1136/bjo.2009.169607 (2011).

Page 6/9 
7. Mahmoudi, S. et al. et. al. Fungal keratitis: An overview of clinical and laboratory aspects., 61 (12), 916-930 https://doi.org/10.1111/myc.12822 (2018).

8. Hsiao, C. H. et al. et. al. Shifting Trends in Bacterial Keratitis in Taiwan: A 10-Year Review in a Tertiary-Care Hospital., 35 (3), $313-317$

https://doi.org/10.1097/IC0.0000000000000734 (2016).

9. CLSI, Clinical Laboratory Standard Institute. Performance standards for antimicrobial susceptibility testing; Twenty-Six Informational Supplement. Document M100-ED19 Wayne,Pa.. 2019

10. Recomendações da Sociedade Brasileira de Patologia Clínica/Medicina Laboratorial (SBPC/ML). Boas práticas em microbiologia clínica. - Barueri, SP: Manole (Minha Editora, 2015).

11. Gray, L. D., Gilligan, P. H. \& Fowler, W. C. Cumitech 13B, Laboratory Diagnosis of Ocular Infections 2011. Coordinating ed. JW Snyder. ASM Press, Washington DC.

12. Cariello, A. J., Passos, R. M., Yu, M. C. \& Hofling-Lima, A. L. Microbial keratitis at a referral center in Brazil. International ophthalmology, 31 (3), 197-204 https://doi.org/10.1007/s10792-011-9441-0 (2011).

13. Ibrahim, M. M. et al. Epidemiology and medical prediction of microbial keratitis in southeast Brazil. Arq Bras Oftalmol, 74 (1), 7-12 https://doi.org/10.1590/S0004-27492011000100002 (2011).

14. Nentwich, M. M. et al. et. al. Clinical and epidemiological characteristics of infectious keratitis in Paraguay. International ophthalmology, 35 (3), $341-346$ https://doi.org/10.1007/s10792-014-9951-7 (2015).

15. Hernandez-Camarena, J. C. et al. et. al. Trends in Microbiological and Antibiotic Sensitivity Patterns in Infectious Keratitis: 10-Year Experience in Mexico City., 34 (7), 778-785 https://doi.org/10.1097/IC0.0000000000000428 (2015).

16. Peng, M. Y., Cevallos, V., McLeod, S. D., Lietman, T. M. \& Rose-Nussbaumer, J. Bacterial Keratitis: Isolated Organisms and Antibiotic Resistance Patterns in San Francisco., 37 (1), 84-87 https://doi.org/10.1097/IC0.0000000000001417 (2018).

17. Hsu, H. Y. et al. Laboratory Results, Epidemiologic Features, and Outcome Analyses of Microbial Keratitis: A 15-Year Review From St. Louis. American journal of ophthalmology, 198, 54-62 https://doi.org/10.1016/j.ajo.2018.09.032 (2019).

18. Tam, A., Côté, E., Saldanha, M., Lichtinger, A. \& Slomovic, A. R. Bacterial Keratitis in Toronto: A 16-Year Review of the Microorganisms Isolated and the Resistance Patterns Observed., 36 (12), 1528-1534 https://doi.org/10.1097/IC0.0000000000001390 (2017).

19. Tan, S. Z. et al. et. al. Twelve-year analysis of microbial keratitis trends at a UK tertiary hospital., 31 (8), 1229-1236 https://doi.org/10.1038/eye.2017.55 (2017).

20. Oliveira-Ferreira, C., Leuzinger-Dias, M., Tavares-Ferreira, J., Torrão, L. \& Falcão-Reis, F. Microbiological profile of infectious keratitis in a portuguese tertiary centre. J Ophthalmol, 24, - https://doi.org/10.1155/2019/6328058 (2019). ї»¿6328058

21. Sagerfors, S., Ejdervik-Lindblad, B. \& Söderquist, B. Infectious keratitis: isolated microbes and their antibiotic susceptibility pattern during $2004-2014$ in Region Örebro County, Sweden. Acta ophthalmologica, 98 (3), 255-260 https://doi.org/10.1111/aos.14256 (2020).

22. Politis, M., Wajnsztajn, D., Rosin, B., Block, C. \& Solomon, A. Trends of Bacterial Keratitis Culture Isolates in Jerusalem; a 13- Years Analysis. PloS one, 11 (11), e0165223 https://doi.org/10.1371/journal.pone.0165223 (2016).

23. Lalitha, P. et al. Trends in bacterial and fungal keratitis in South India, 2002-2012. The British journal of ophthalmology, 99 (2), 192-194 https://doi.org/10.1136/bjophthalmol-2014-305000 (2015).

24. Suwal, S. et al. Microbiological profile of corneal ulcer cases diagnosed in a tertiary care ophthalmological institute in Nepal. BMC Ophthalmol, 16,209 https://doi.org/10.1186/s12886-016-0388-9 (2016).

25. Mun, Y., Kim, M. K. \& Oh, J. Y. Ten-year analysis of microbiological profile and antibiotic sensitivity for bacterial keratitis in Korea. PloS one, 14 (3), e0213103 https://doi.org/10.1371/journal.pone.0213103 (2019).

26. Lin, L. et al. Nine-Year Analysis of Isolated Pathogens and Antibiotic Susceptibilities of Infectious Endophthalmitis from a Large Referral Eye Center in Southern China. Infection and drug resistance, 13, 493-500 https://doi.org/10.2147/IDR.S235954 (2020).

27. Watson, S. et al. Keratitis antimicrobial resistance surveillance program, Sydney, Australia: 2016 Annual Report. Clinical \& experimental ophthalmology 47(1), 20-25. https://doi.org/10.1111/ceo.13364 (2019).

28. Ung, L., Bispo, P., Shanbhag, S. S., Gilmore, M. S. \& Chodosh, J. The persistent dilemma of microbial keratitis: Global burden, diagnosis, and antimicrobial resistance. Survey of ophthalmology, 64 (3), 255-271 https://doi.org/10.1016/j.survophthal.2018.12.003 (2019).

29. Wong, T., Ormonde, S., Gamble, G. \& McGhee, C. N. Severe infective keratitis leading to hospital admission in New Zealand. The British journal of ophthalmology, 87 (9), 1103-1108 https://doi.org/10.1136/bjo.87.9.1103 (2003).

30. Lim, S. A., Na, K. S. \& Joo, C. K. Clinical Features of Infectious Keratitis Caused by Propionibacterium Acnes. Eye \& contact lens, 43 (5), $330-333$ https://doi.org/10.1097/ICL.0000000000000281 (2017).

31. Das, S., Rao, A. S., Sahu, S. K. \& Sharma, S. Corynebacterium spp as causative agents of microbial keratitis. The British journal of ophthalmology, 100 (7), 939-943 https://doi.org/10.1136/bjophthalmol-2015-306749 (2016).

32. Farrell, S., McElnea, E., Moran, S., Knowles, S. \& Murphy, C. C. Fungal keratitis in the Republic of Ireland., 31 (10), 1427-1434 https://doi.org/10.1038/eye.2017.82 (2017).

33. Sagerfors, S., Ejdervik-Lindblad, B. \& Söderquist, B. Does the sampling instrument influence corneal culture outcome in patients with infectious keratitis? A retrospective study comparing cotton tipped applicator with knife blade. BMJ Open Ophthalmol, 5 (1), e000363 https://doi.org/10.1136/bmjophth-2019000363 (2020).

34. Manisha, A., Hussain, F. J., Shikha, J. \& Umang, M. Pearls and paradigms in infective keratitis. Rom J Ophthalmol, 63, 119-127 https://doi.org/10.22336/rjo.2019.18 (2019). 
35. Agarwal, R. et al. Impact of COVID-19 pandemic, national lockdown, and unlocking on an apex tertiary care ophthalmic institute. Indian J Ophthalmol, 68 (11), 2391-2395 https://doi.org/10.4103/ijo.IJO_2366_20 (2020).

\section{Figures}
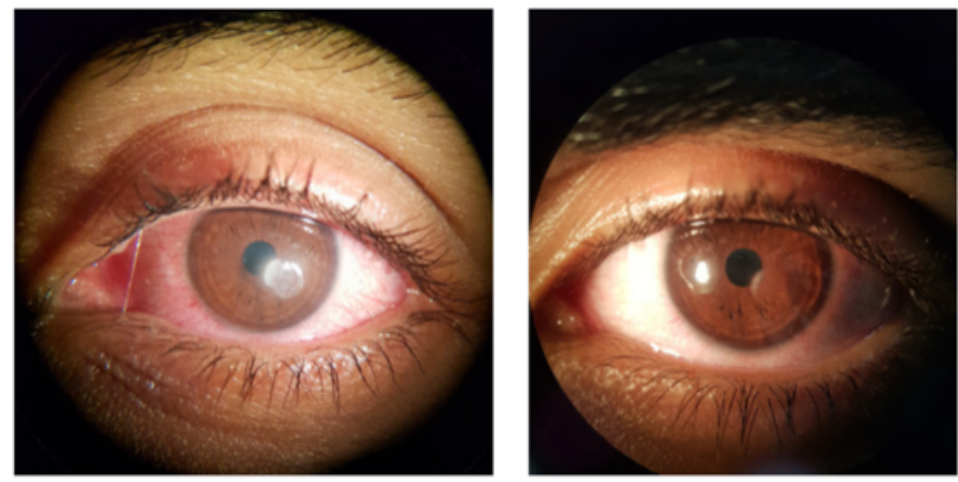

Figure 1

Staphylococcus epidermidis keratitis: diagnosis at an early stage and proper treatment. Pictures: João Felippe Bertocco MD
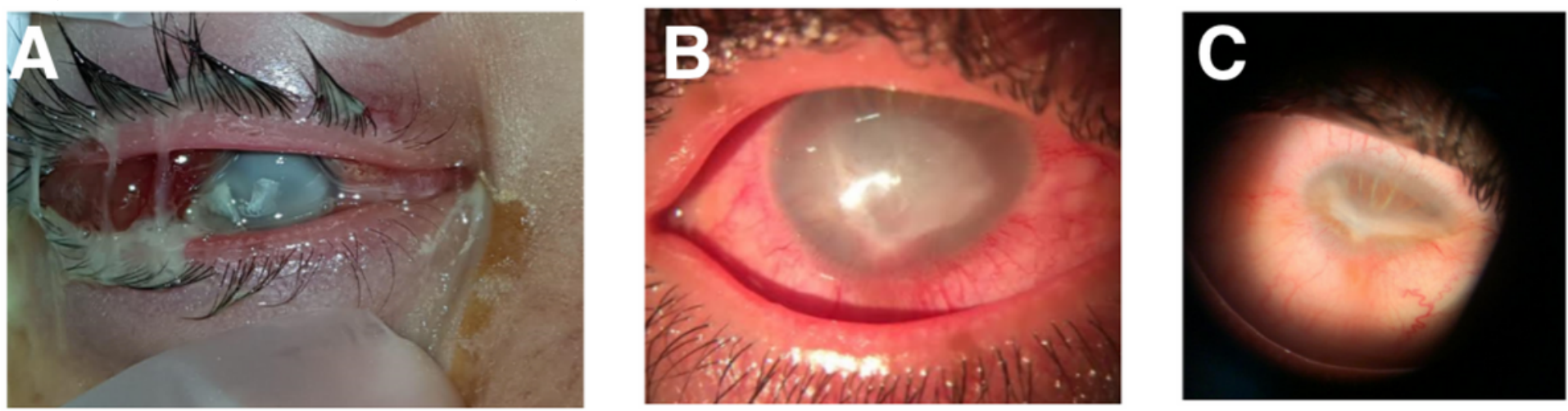

Figure 2

Severe microbial infection resulted in phthisis bulbi. Corneal scrape was not performed because of risk of perforation. A: Initial presentation. The patient underwent corneal suture and anterior chamber washout; B. 40 days after the first exam; C: 4 months after first exam: phthisis bulbi. Pictures: A, C: Juliana Mika Kato MD; B: Luiza Manhezi Shin de Oliveira MD
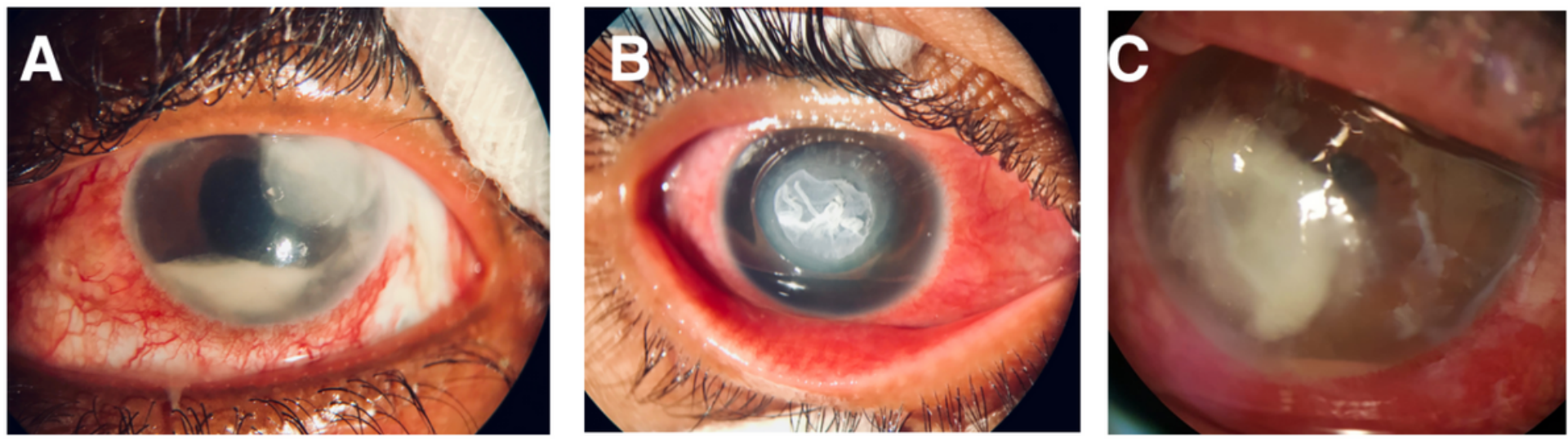

Figure 3

A. Streptococcus pneumoniae infection in a blind eye (previous rhegmatogenous retinal detachment); B. Acanthamoeba necrotizing keratitis in a contact lens wearer; C. Mycotic keratitis caused by Fusarium solani. Pictures: A, B: Daniel de Souza Costa MD; C: Fernanda Cristina Bakkar MD

\section{Supplementary Files}

This is a list of supplementary files associated with this preprint. Click to download. 
- Graphic1.png

Page 9/9 